\title{
Um Sistema para \\ Programação de uma Estação FM
}

\author{
Márcio Samamede de Oliveira \\ Paulo Oswaldo Boaventura Netto \\ Rogério de Campos Teixeira
}

COPPE/UFRJ, Programa de Engenharia de Produção

Caixa Posta. 68507, Cep 21945 Rio de Janeiro, RJ

Palavras chave: Teoria dos Grafos, Pesquisa Operacional, Otimização

Key words: Graph Theory, Operations Reserarch, Optimization

RESUMO

O problema da programação musical de uma estação FM é aqui estudado como o da especificação de um certo número de sequèncias de quatro músicas em uma ordem de classificação dada, como: Música instrumental brasileira; Música vocal brasileira; Música instrumental estrangeira; Música vocal estrangeira.

A seleção de sequéncias utilizáveis deve levar em conta dois tipos de restrições. O primeiro tipo é objetivo e diz respeito ao tempo utilizado por uma sequência, que deve estar entre limites mínimo e máximo dados. O segundo tipo é subjetivo e depende das preferências do programador(a), em relação ao tipo de música, ou intérprete, que ele considera "bom" para ser executado antes ou depois de algum outro.

O problema pode ser modelado por um grafo no qual cada música corresponde a um vértice, sendo o conjunto de vértices particionado pelas diferentes classes de músicas. Cada sequêencia será, então, associada a um caminho no grifo. Um algoritmo destinado a produzir um conjunto de sequêencias que atenda às restriçōes é descrito.

\section{ABSTRACT}

The problem of music programming in a FM-rádio station can be structured as that of producing a certain number of 4-music sequences with a given ordering by given classes, such as Brazilian instrumental music; Brazilian vocal music; Foreign instrumental music; Foreign vocal music.

To select suitable sequences, one has to take account of two types of constraints. The first type is an objective one and deals with the time consumed by a sequence, which has to be between given maximum and minimum limits. The second type is subjective and depends on the programmer's preferences in what he/she thinks it is, or not, "good" to play a given type of recording before or after another one.

The problem can be modelled by a graph where each music is a vertex, the vertex set being partitioned among the specified classes. Each 4-music sequence will then be associated to a path in the graph. An algorithm is described to find a set of sequences according to the given constraints. 


\section{O Programa}

Um programador de uma rádio $\mathrm{FM}$ dispõe de um acervo de aproximadamente 160 discos, dos quais selecionou cerca de 800 músicas, com as quais deve compor a programação diária da emiossora. Esta programação ocupa aproximadamente 10 horas diárias e é dividida em 40 seqüências, cada uma composta por 4 músicas, classificadas da seguinte maneira:

- Música Popular Brasileira ( Instrumental )..... MPBI

- Música Popular Brasileira ( Vocal ). MPBV

- Música Popular Estrangeira ( Instrumental )... MPEI

- Música Popular Estrangeira ( Vocal ). MPEV

Na seleção das seqüências, o programador deve levar em conta duas restrições. A primeira, de natureza objetiva, exige que cada sequiência tenha uma duração entre 14 e 16 minutos. Este limite envolve o fato de que as sequiências musicais são alternadas com seqüências de comerciais com uma duração determinada. A ocorrência de "folgas" nas sequiências, corresponde no final do dia a "tempos mortos" que deverão ser preenchidos com mais músicas ou vinhetas da rádio.

A outra restrição é de ordem subjetiva e depende, naturalmente, de cada programador. A ordem das classes de música numa sequiência é constante, mas o programador acha que algumas músicas não devem ser seguidas (ou precedidas) por outras. Por exemplo: "depois de uma Elba Ramalho não pega bem um Duke Ellington".

Todos os discos à disposição do programador estão listados, bem como as cançães selecionadas em cada um deles, e mais algumas outras informações, incluindo a duração ( em minutos e segundos ).

Exemplo:

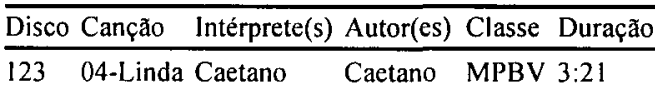

referenciada, como 123MPBV-04; 3:21.

No processo habitual a seleção é feita tentativamente, com o auxílio de uma calculadora. Quando a duração de uma seqüência atinge a faixa determinada, ela é anotada e passase à busca da seqüência seguinte. São organizadas quatro pilhas de ficas com as músicas ordenadas segundo a classificação já vista. Assim, algumas seqüências podem ser as seguintes:

124MPBI-04; 068MPBV-37; 120MPEI-12; 055MPEV-19 (14:23) 008MPBI-45: 101MPBV-16; 160MPEI-44; 001MPEV-49 (15:07)

O objetivo deste trabalho é descrever a teoria e a estruturação de um programa de computador, capaz de gerar a programação musical da rádio, atendendo não apenas aos limites inferior e superior de duração, mas também às preferências do programador, de maneira rápida e eficiente.

\section{A Teoria e o Modelo}

O problema é modelado com o auxílio da Teoria dos Grafos e para a compreensão do modelo, torna-se necessária colocação inicial de alguns conceitos básicos da teoria.

Diremos que um grafo (orientado) $\mathrm{G}=$ $(\mathrm{X}, \mathrm{U})$ é um par no qual $\mathrm{X}$ é um conjunto 
discreto finito de elementos chamados vértices ou nós e U é um conjunto de pares ordenados $(x, y)$, onde $x, y \in X$, chamados arcos. Se existir um $\operatorname{arco}(x, y)$ os vértices $x$ e y são ditos adjacentes e, se existirem $\operatorname{arcos}(x, y)$ e $(y, z)$ eles serão ditos também adjacentes. Um arco é valorado se a ele se associa um elemento de um conjunto numérico $\mathrm{V}$; se um grafo possui arcos valorados ele será um grafo valorado.

Um caminho $\mu_{x y}=(x, a, b, \ldots, s, t, y)$ é uma seqüência de arcos adjacentes dois a dois que se inicia num vértice $x$ e termina num vértice $y$. O valor de um caminho corresponde à soma dos valores de seus $\operatorname{arcos}$. Se $\mathrm{x}=\mathrm{y}$ o caminho é fechado e se chama circuito.

Se um grafo não possuir circuitos, existirá uma partição $N=\left\{N_{L} \mid=1, \ldots . r\right)$ do seu conjunto de vértices cujos elementos são chamados níveis e tal que $\forall \mathrm{i}, \mathrm{j}, \mid 1 \leq \mathrm{i} \leq \mathrm{j} \leq \mathrm{r}, \exists /(\mathrm{x}, \mathrm{y}) \in$ $U \operatorname{com} x \in N_{j}$ e $y \in N_{i}$.

O problema pode ser modelado associando-se um vértice a cada música e levando-se em conta a partição do conjunto de músicas nos 4 tipos descritos; uma vez que se deseja obter um conjunto de seqüências de músicas, cada uma delas poderá ser associada a um caminho. Então se considerará um grafo sem circuitos, ao qual se adicionarão vértices fictícios $\mathrm{fe}$, sendo os caminhos a serem procurados do tipo $\left(f, x_{L}, x_{J}, x_{L} s\right)$. haverá então seis níveis, logo $N=\{\{f\}, M P B I, M P B V, M P E I$, $\mathrm{MPEV},\{\mathrm{S}\}\}$ e os $\operatorname{arcos}\left(f, x_{\mathrm{L}}\right)$ terão valor zero enquanto um arco $\left(x_{p}, x_{q}\right)$ terá o valor da duração da música $(\{)(p=i, j, k$, ou l, $q=j, k$, I ou $\left(\mathrm{x}_{\mathrm{q}}\right)=\mathrm{s}$ ). O valor de um caminho $(\mid)$ qualquer será então dado pela soma das durações das músicas correspondentes e um dado caminho será viável se seu valor estiver dentro dos limites de tempo considerados.
Se o programador desejar excluir a possibilidade de execução sequencial de duas músicas $x_{p} \in N_{1}$ e $x_{q} \in N_{1+1}$, bastará não incluir no grafo o $\operatorname{arco}\left(x_{p}, x_{q}\right)$.

Modelar este problema através de grafos significa basicamente tratá-lo como um problema de caminhos. O grafo já se encontra estruturado em niveis e evidentemente é um grafo sem circuitos.

Os níveis $N_{1}, N_{2}, N_{3}$ e $N_{4}$ representam as classes de músicas, os arcos são valorados pela duração das músicas e os vértices representam as músicas. Do vértice fonte a qualquer vértice do nível 1 a "duração" é zero. Entre $N_{1}$ e $N_{2}$ ela é $t_{1}$, entre $N_{2}$ e $N_{3}$ de $t_{2}$, entre $N_{3}$ e $N_{4}$ de $t_{3}$ e entre $N_{4}$ e o vértice sumidouro de $t_{4}$ (em minutos). A soma $T=t_{1}+t_{2}+t_{3}+t_{4}$ deve obedecer à restrição $14 \mathrm{~min} .(\%) \mathrm{T}(\%)$ 16 min. para que uma seqüência (um caminho) seja viável. Devemos então, achar 40 caminhos viáveis entre $f e s$, para compor a programação de um dia (Pode-se notar que em ausência de restrições de seqüências, o número de caminhos entre $\mathrm{f}$ e $\mathrm{s}$ será igual ao produto dos cardinais dos níveis de $\mathrm{N}_{1}$ a $\mathrm{N}_{2}$ que presumivelmente é um valor muito elevado).

As preferências do programador são explicitadas através da matriz de adjacência do grafo. A existência (ou não) de um arco entre um vértice de um nivel $N_{k}$ e um vértice do nível $N_{k+1}$ indica "se uma música $X \in N_{k}$ pode ser tocada (ou não) antes de uma $Y \in N_{k+1}$ ".

$\mathrm{O}$ número de vértices não tem que ser necessariamente igual para todos os níveis, ou seja, número de músicas selecionadas para cada classe não é necessariamente igual.

Os problemas de caminhos são bastante explorados na Teoria dos Grafos e particular- 
mente em suas aplicações na Pesquisa Operacional. Todavia os algoritmos existentes para a solução desta classe de problemas não se prestam para o problema em questão, pois não se trata de buscar o caminho mais curto entre dois vértices ou mesmo os $\mathrm{K}$ caminhos mais curtos. O que se quer, como já foi dito, é obter $\mathrm{n}$ caminhos com um comprimento compreendido entre dois limites. O algoritmo desenvolvido para este problema tem como origem o algoritmo PERT (Program Evaluation and Review Technique) como será mostrado na seção seguinte.

\section{O Algorítimo}

Trata-se de uma adaptação do algoritmo PERT; essa opção foi adotada em vista do interesse em se minimizar a folga entre duração de uma seqüência de quatro músicas e o valor máximo de 16 minutos. Por outro lado, uma dada seqüência pode ter duração acima desse valor e esse é um dos motivos que levam à necessidade da introdução de novos mecanismos no PERT.

Se for encontrado um caminho viável, o algoritmo o registrará e, em seguida, eliminará do grafo os quatro vértices dele constantes, correspondentes à músicas assim escolhidas as quais, em vista disso, não mais se repetirão na programação.

No caso de empate entre dois caminhos críticos viáveis, o retraçamento será feito através dos vértices de menor semigrau exterior; com isso, a futura eliminação do caminho escolhido (se viável) causará a menor perturbação possível na estrutura do grafo.

$O$ algoritmo funcionará enquanto existir um subgrafo conexo de $\mathrm{G}$ que contenha a fonte e o sumidouro; por outro lado, as soluções obtidas somente terão interesse enquanto seu valor for igual ou superior a 14 minutos.

Se encontrar um caminho crítico inviável com duração acima de 16 minutos, o algoritmo eliminará um arco desse caminho (o que chamaremos um corte), abrindo assim a possibilidade do encontro de novo caminho.

Procurando-se manter disponível o maior número possível de alternativas para a interação seguinte, a realização de um corte será feita da seguinte forma:

a) o corte é feito em um vértice do caminho que tenha semigrau exterior máximo, excluida a fonte; dessa forma, procura-se evitar inutilizar um vértice como ponto de passagem, o que tornaria inviável a sua escolha futura;

b) uma vez feito um corte e achado um novo caminho que seja viável, o arco cortado é restabelecido. Isto poderá, ou não, trazer de volta o mesmo caminho inviável em outra interação, conforme a estrutura do subgrafo restante;

c) a eliminação dos vértices de um caminho viável poderá ter como conseqüências a anulação do semigrau exterior de algum vértice (se ele tiver apenas um sucessor que esteja sobre o caminho). Este vértice, que se terá tornado pendente, não mais poderá figurar em qualquer seqüência futura e deverá, portanto, ser eliminado. Cabe observar que essa eliminação melhorará o critério de corte citado acima, evitando a seleção equivocada, pelo valor do semigrau exterior, de um vértice que tem na verdade menos possibilidades de passagem do que aparenta. Ver a figura a seguir: 


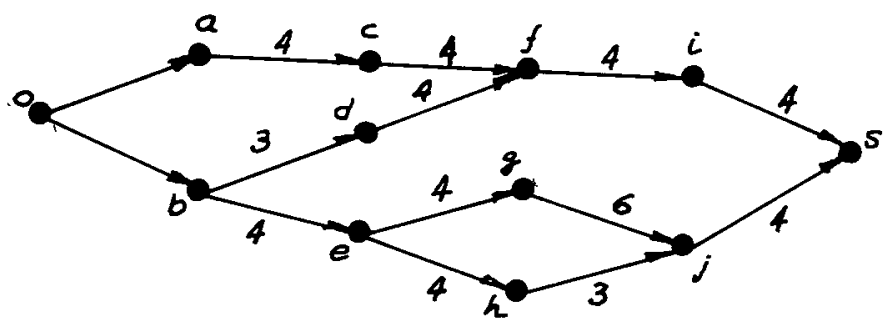

A primeira escolha é (b, e, g, j) inviável. Se o corte for em $b,(b, e)$ será eliminado e a segunda escolha será (a, c, f, i), viável. A eliminação desses vértices torna d pendente; se ele não for eliminado, $(b, d)$ contará para o semigrau exterior de $b$ apesar de não ser de fato uma alternativa de passagem e, com a reposição de (b,e), b será de novo escolhido para corte - o que impedirá a escolha de outro caminho viável, no caso (b, e, h, j).

O algoritmo pode ser descrito, resumidamente, da seguinte forma:

1) Refazer os cortes existentes, se for o caso;

2) Determinar o valor do maior caminho para cada vértice (correspondente à "data mais cedo" do PERT);

se o sumidouro não for atingido, fim.

se o valor obtido para o sumidouro for inferior a 14 , fim.

3) Determinar o valor do menor caminho de cada vértice ao sumidouro (correspondente à "data mais tarde" do PERT);

4) Retraçar um caminho crítico;

- se existir um caminho viável, desempatar pelo semigrau exterior

se necessário; guardar a solução, eliminar os vértices do caminho e os vértices pendentes; voltar a (1);

- se o caminho for inviável com valor $>16$, procurar um vértice de semigrau exterior máximo sobre o caminho e fazer o corte do arco que ele possui no caminho; voltar a (2);

Enfim, convém notar que a ordem de escoIha deve ser modificada a cada nova programação, de modo a evitar que o algoritmo a repita. Isto pode ser convenientemente feito, utilizando-se um vetor intermediário de índices para cada nível do grafo, sobre o qual deverá ser gerada uma permutação por uma rotina conveniente, baseada na geração de números pseudo-aleatórios.

\section{Conclusões}

Apresentamos um modelo, implementado em um programa utilizável em microcomputadores, que visa auxiliar o trabalho de programação musical em estações de rádio, sempre que o programador se utilize de uma seqüência fixa de tipos de música a cada intervalo. A montagem de cada modelo específico é feita pelo programa com base na entrada de dados feita pelo programador, a 
qual inclui a eventual indicação de restrições sobre a sequenciação a ser feita.

O resultado de uma corrida do modelo é uma coleção de seqüência de quatro músicas, que constitui uma programação (p. ex., para um mês).

A implementação do modelo é apenas básica, mas ele pode servir de núcleo para um utilitário eficiente; o preparo deste, no entanto, não estava nos objetivos deste trabalho.

Em relação às bases teóricas, entendemos que o trabalho abre novos caminhos para a utilização da teoria dos grafos, em um contexto habitualmente distanciado dessas aplicações.

\section{Referências \\ Bibliográficas}

NETTO, P. O. Boaventura: Teoria e Modelos de Grafos, SP., Ed. Edgard Blucher, 1979.

HILLIER, F. S e LIEBERMAM, G. J.: Introdução à Pesquisa Operacional; Ed. Campus, RJ, 1988.

HARARY, F.: Graph Theory; Addison-Wesley, 1971.

BERGE, C.: Graphes et Hypergraphes; Dunodm, 1973. 